\title{
Histórias em quadrinhos, filosofia pop e filosofia política: a América da Liberdade versus os Estados Unidos da Verdade em "Uncle Sam"
}

HERALDO APARECIDO SILVA

\section{Resumo}

O presente artigo tem por objetivo analisar a minissérie em quadrinhos U.S. Tio Sam, de Steve Darnall e Alex Ross (1998), a partir da filosofia pop de McLaughlin (2005) e Goodenough (2005), e da filosofia política de John Rawls (2000) e Robert Nozick (1991). Primeiramente, o estudo foca na descrição da obra para, em seguida, apresentar as perspectivas filosóficas que servem de aporte teórico analítico. A fundamentação teórica baseia-se em autores como: Eco (1993), Mix (1997), Eisner (1999), Moya (1994; 2003), McLaughlin (2005); Goodenough (2005), Vergueiro

Palavras-chave: Quadrinhos, filosofia pop, filosofia política e Ramos (2009), dentre outros. A leitura filosófica a partir das ideias de Rawls (2000) e Nozick (1991) ocorre mediante a interpretação de temas extraídos da história em quadrinhos. 


\section{Comics, pop philosophy and political philosophy: America's Freedom versus the United States of Truth in "Uncle Sam"}

\begin{abstract}
This article analyses the graphic novel U.S. Uncle Sam, by Steve Darnall and Alex Ross (1998), starting from the pop philosophy of McLaughlin (2005) and Goodenough, (2005) and the political philosophy of John Rawls (2000) and Robert Nozick (1991). First, the study focuses on the description of the work to then present the philosophical perspectives that function as analytical theoretical support. The theoretical foundation is based on authors such as: Eco (1993), Mix (1997), Eisner (1999), Moya (1994; 2003), McLaughlin (2005); Goodenough (2005), Vergueiro and Ramos (2009), among others. A reading from the philosophical ideas of Rawls (2000) and Nozick (1991) occurs through the interpretation of extracted themes of the comic book.
\end{abstract}

Keywords:

Comics, pop philosophy, political philosophy 


\section{Historietas, filosofía pop y filosofía política: la América de la Libertad \\ frente a los Estados Unidos de la Verdad en "Uncle Sam"}

HERALDO APARECIDO SILVA

\section{Resumen}

Este artículo tiene el objetivo de analizar la miniserie en historietas U.S. Tio Sam, de Steve Darnall y Alex Ros (1998), a partir de la filosofía pop de McLaughlin (2005) y Goodenough (2005), de la filosofía política de Jhon Rawls (2000) y Robert Nozick (1991). En primer lugar, el estudio se centra en la descripción de la obra para, luego, presentar las perspectivas filosóficas que sirven de marco teórico analítico. La base teórica se fundamenta en autores como: Eco (1993), Mix (1997), Eisner (1999), Moya (1994; 2003), McLaughlin (2005); Goodenough

Palabras-clave: Historietas, filosofía pop, filosofía política (2005), Vergueiro y Ramos (2009) entre otros. La lectura filosófica de las ideas de Rawl (2000) y Nozic (1991) se produce a través de la interpretación de temas extraídos de las historietas. 


\section{Introdução}

No campo da crítica filosófica, durante quase três décadas a leitura dos quadrinhos foi bastante tendenciosa e limitada em termos teóricos, visto que, basicamente, as abordagens das HQs eram feitas mediante os aportes teóricos do marxismo (Marx, Escola de Frankfurt, Althusser), da semiótica (Peirce, Eco) e da semiologia (Saussure, Barthes, Propp). Em grau menor, também era possível encontrar artigos esparsos que discorriam sobre quadrinhos a partir de outros aportes teóricos, como a Psicanálise (Freud, Jung), a Fenomenologia (Husserl, Merleau-Ponty), o Existencialismo (Sartre), além de estudos baseados em autores isolados como: Nietzsche, Heidegger, Bachelard e Deleuze (MARNY, 1970; NEOTTI, 1971; CAGNIN, 1975; MOYA, 1977; LUYTEN, 1985; ECO, 1993; CIRNE, 2000).

Durante as décadas de 70 e 80 , até meados dos anos 90 do século XX, esse foi o padrão das chamadas leituras críticas que, invariavelmente, repetiam exaustivamente os mesmos temas (ideologia, alienação, comunicação, forma, conteúdo, leitura e letramento, estrutura, semântica, narrativa) e concorriam entre si, alguns abertamente e outros sub-repticiamente, pela posse da leitura correta e cabal das histórias em quadrinhos (NEOTI, 1973; CIRNE, 1974; DORFMAN; JOFRÉ, 1978; DORFMAN; MATTELART, 1980; CALAZANS, 1997).

A partir dos anos 2000, uma iniciativa norte-americana e europeia que visava a popularização da filosofia, vista até então como algo acadêmico e árido, buscou humanizar os grandes vultos da história da filosofia e abordar temas atuais a partir da perspectiva filosófica mediante elementos não filosóficos. Dentre tais elementos, se destacavam filmes, músicas, histórias em quadrinhos, literatura, poemas, documentários, romances filosóficos, seriados televisivos, desenhos animados, cafés filosófi- 
cos e temas do cotidiano. Essa abordagem filosófica terapêutica e prática ficou conhecida como Filosofia Pop (MARINOFF, 2006; ROSS, 2006; BAGGINI, 2008; ROOS, 2008; CATHCART; KLEIN, 2008; POWERS, 2012; COHEN, 2012).

Em virtude da delimitação temática, não trataremos aqui das polêmicas em torno das distinções feitas a partir da noção originária de pop filosofia de Deleuze (1998). Registramos, no entanto, que a nomenclatura filosofia pop não é um ponto pacífico na comunidade filosófica. Inclusive, há quem defenda a necessidade de se estabelecer cisões entre tipos de filosofia pop, em virtude das concepções subjacentes aos questionamentos, abordagens e procedimentos defendidos por seus praticantes. Também a respeito disso, é preciso notar que muitos intelectuais ou expertises filosóficos que atuam junto ao grande público (programas televisivos, colunas de jornal, revistas não acadêmicas, sites e outras mídias) não consideram o seu trabalho como uma expressão da filosofia pop (OLIVEIRA, 2015). Assim, alguns estudiosos sustentam que é possível dividir esquematicamente a filosofia pop em três variantes: a filosofia pop boa (criativa); uma filosofia pop má (comercial); e uma filosofia pop relutante (que não se reconhece como tal).

Então, em conformidade com os objetivos do presente artigo, suspenderemos a discussão acerca do estatuto da filosofia pop para praticar a filosofia pop, pois no âmbito dessa proposta é possível ampliar consideravelmente o escopo temático passível de articulação com o universo das histórias em quadrinhos e abdicar da pretensão de elaborar qualquer leitura crítica que se arrogue como completa e definitiva. Em linhas gerais, é nessa perspectiva que transladamos do campo cinematográfico para o campo das HQs o enfoque sugerido por Goodenough (2005), cuja abordagem propõe que os filmes podem: ilustrar teorias filosóficas; ser sobre filosofia; e ser filosofia.

Essa diretriz também coincide com a proposta de McLaughlin (2005) sobre a abordagem dos quadrinhos como filosofia. E também é nessa linha de estudos que apresentaremos posteriormente a nossa interpretação acerca da obra quadrinizada U.S. Tio Sam, de Steve Darnal e Alex Ross.

\section{Caracterização das Histórias em Quadrinhos}

As histórias em quadrinhos são formadas por dois elementos inter-relacionados: a imagem e o texto. A originalidade do sistema narrativo da arte sequencial reside nesta relação imagé- 
tica e textual (EISNER, 1999). Nesse caso, a exceção é feita por algumas variantes de $\mathrm{HQ}$, como a tira e a charge que, muitas vezes, não empregam a linguagem escrita. A relação entre os aspectos linguísticos (textos) e icônicos (imagens) dos quadrinhos constitui a sua essência (ECO, 1993).

Embora a harmonia entre os dois tipos de signos gráficos, o imagético e o textual, seja determinante para a produção de uma boa história em quadrinhos (visto que desenhos malfeitos comprometem um bom roteiro, tanto quanto textos ruins comprometem belas imagens), isto não significa que haja um padrão definido, uma forma única ou canônica de como uma HQ deve ser (MOYA, 1994; CIRNE, 2000).

Em contrapartida, há quem sustente a ideia dogmática segundo a qual deveria ser fixado um molde definitivo para a produção de quadrinhos. Acreditamos que tal ensejo é apenas uma tentativa sub-reptícia de cercear a imaginação artística. Talvez a melhor maneira de tratar esta questão e dissolver a polêmica seja considerar a $9^{a}$ arte através da ideia que pressupõe a existência de graus de quadrinização (CAGNIN, 1975).

A transformação constante das HQs e a permanente vividez de sua arte e de sua narrativa é, conforme acreditamos, um feliz resultado da evolução técnica/tecnológica (repografias, desenhos, fotografias, colagens e diversas técnicas de pintura) e dos recursos textuais (estilística, simbolismos, formas literárias e vários elementos linguísticos) combinados com a primazia da liberdade criativa de roteiristas e desenhistas que usam a arte, o balão, a legenda e a onomatopeia para expandir as dimensões do conteúdo e da forma (McLAUGHLIN, 2005; RAMOS, 2010).

Dentre as inúmeras denominações usadas para designar as histórias em quadrinhos, temos: HQ, gibi, romance gráfico, arte sequencial, quadrinhos, $9^{\mathrm{a}}$ arte etc. Em 2016, se comemora 120 (cento e vinte) anos de quadrinhos, conforme a data convencional de sua origem (1896), celebrada em quase todo o mundo (MOYA, 1994).

Nos Estados Unidos da América, a denominação mais comum para os quadrinhos é comics, embora sejam usados também os termos comic books, graphic novel e sequential art. A despeito de sua vasta produção temática, os quadrinhos norte-americanos se notabilizaram mediante a divulgação do gênero cômico infantil da Disney e do super-heroísmo da Marvel e DC, marcas amplamente difundidas no mercado editorial de quadrinhos e que conseguiram uma considerável inserção em outras mídias (MIX, 1997; MOYA, 2003). 
Na Europa, existe uma terminologia diversificada e cambiante para designar as HQs que tematizam principalmente a história, a política, o erotismo, a ficção e a fantasia; na Itália, são conhecidos como fumetti; na França, são chamados de bandes dessinéss; em Portugal, são tratados como histórias aos quadradinhos; na Espanha, são cognominados de tebeos. Em quase todos os países da América Latina os quadrinhos são chamados de historietas e sua temática assemelha-se aos tópicos abordados nos tebeos espanhóis. Na Argentina, Chile, Cuba e México, por exemplo, a ênfase reside nas questões políticas e nos quadrinhos de humor (LUYTEN, 1987; MOYA, 2003).

Já os quadrinhos originários do Japão, denominados de mangás, são considerados bastante originais tanto na forma quanto no conteúdo, pois os desenhos mais estilizados e a técnica inovadora conferem maior dinamismo narrativo, constituindo uma evolução na linguagem imagética dos quadrinhos; com suas metáforas visuais, convenções iconográficas e símbolos cinéticos (LUYTEN, 1991; MOYA, 2003).

Finalmente, no Brasil, os quadrinhos, gibis, ou simplesmente HQs, são bastante conhecidos e apreciados. Todavia, embora a avidez brasileira nos situe entre os três maiores países consumidores de quadrinhos, a produção nacional ainda é relativamente escassa e com pouca projeção internacional. A razão disso não decorre em virtude da falta de talento, pois muitos artistas trabalham ou produzem nos EUA e Europa, mas em decorrência do fato da produção nacional ser bastante dificultada.

Aqui ainda se publica poucos quadrinhos em comparação ao material que é importado das grandes editoras mundiais de quadrinhos. Ainda há falta de estrutura tanto na produção quanto na distribuição para se competir com os quadrinhos internacionais. Exceções são poucas, uma delas é Maurício de Souza, que conquistou uma importante fatia do mercado editorial brasileiro e, de modo similar ao império Disney, expandiu sua Turma da Mônica para diversos países como Argentina, Alemanha, Bélgica, Canadá, Espanha, França, Holanda, Inglaterra, Itália, Uruguai, dentre outros.

A partir de meados dos anos 9o, este cenário começa a mudar devido, principalmente, a revolução tecnológica protagonizada pelo advento da internet (CALAZANS, 1996). Muitos talentos que em outros tempos somente lograriam um tímido êxito após árdua luta mediante o abnegado trabalho artesanal de fanzines, agora conseguem ganhar visibilidade em sites próprios para divulgação de seus trabalhos (MAGA- 
LHÃES, 2012). Nos dias atuais, graças a esse novo contexto, proporcionado pela transição das histórias em quadrinhos da mídia impressa para a mídia digital, é possível encontrar algumas iniciativas interessantes e que merecem ser destacadas, como o Catarse e outros projetos similares de captação voluntária de recursos voltado para o financiamento coletivo de produções quadrinísticas.

No campo educacional a relevância das HQs é expressa pela sua significativa presença nas instituições escolares, tanto como atividade de leitura quanto em práticas pedagógicas utilizadas nas salas de aula (RAMA; VERGUEIRO, 2007). Diante desse novo cenário em que a presença das HQs no ambiente escolar passa a ser incentivado por uma gradativa inserção quadrinística na educação brasileira como política educacional mediante os Parâmetros Curriculares Nacionais (PCN) e o Programa Nacional Biblioteca na Escola (PNBE), um desafio constante para professores e pesquisadores passa a ser a compreensão correta da linguagem, dos recursos e das principais obras no campo das histórias em quadrinhos (VERGUEIRO; RAMOS, 2009).

\section{Tio Sam: figura histórica, ícone cultural e história em quadrinhos}

Para evitar mal-entendidos, é preciso enfatizar que Tio Sam já fazia parte da história e da cultura norte-americana bem antes de sua "participação" na Primeira Grande Guerra. A origem do nome Uncle Sam é atribuída a um episódio ocorrido no início do século XIX, enquanto EUA e Reino Unido se confrontavam pela segunda vez na guerra de 1812-1814. Sam Wilson, um dos fornecedores de carne para o exército norte-americano, também era conhecido pelo apelido de Uncle Sam. Como as iniciais de sua alcunha "US" eram as mesmas usadas para identificar algo que fosse "propriedade do governo", em pouco tempo, as pessoas jocosamente ou espirituosamente passaram a sinonimizar US como Uncle Sam/United States.

A figura do Tio Sam obteve projeção internacional quando os EUA (no original em inglês "U.S.", como uma dupla referência a United States e Uncle Sam) romperam a neutralidade e ingressaram na Primeira Guerra Mundial. Entretanto, esta não é a única versão do lendário personagem. A austera e intimidadora imagem do Tio Sam de 1917, convocando homens para o exército norte-americano, celebrizou-se através de um cartaz, amplamente difundido nos EUA e em diversos 
outros países, no qual aparecia um homem branco, grisalho e de olhar severo, trajando terno e cartola nas cores vermelho, azul e branco, com o dedo indicador em riste conclamando: "I want you for U.S. Army!". Essa famigerada figura foi criada por James Montgomery Flagg.

Já em relação ao desenho da personagem, grosso modo, o que ocorreu foi uma "sofisticação" na sua imagem original, de 1838 (que antes era caricatural, visto que sua área de atuação primeva era a dos cartoons políticos de Thomas Nast), e uma alteração em suas funções, pois, se antes ocupava uma posição de crítica e de destaque em relação aos problemas estritos de seu país, satirizando-os; a partir dos resultados da Primeira Grande Guerra e da reconfiguração da ordem mundial, quando os EUA emergem como potência econômica e política, a figura passa a simbolizar para o resto do mundo, primeiro, os ideais e a força deste país e, depois, o imperialismo.

A respeito disso, podemos destacar, por exemplo, que em 1877, charges do Tio Sam foram publicadas em Nova Iorque no semanário humorístico Puck. Nesta ocasião, o referido personagem foi apresentado como uma espécie de defensor de Cuba contra os guerrilheiros da época, além de ser mostrado de modo simpático em relação aos patriotas cubanos que estavam em guerra pela libertação contra a Espanha, que era a sua colonizadora na época (FERNANDES, 1977).

Há também um Tio Sam criado por Will Eisner e Lou Fine. Trata-se de um super-herói que "militou" do início da década de 1940 até o final de 1944, sob o selo da antiga editora Quality Comics. Esta versão do Tio Sam incorporava o espírito da nação americana, possuía super força, um relativo grau de invulnerabilidade e era capaz de viajar para outras dimensões através de vórtices tricolores (azul, vermelho e branco). Tais poderes eram idealisticamente derivados da consciência americana e declinavam conforme o povo americano perdia a fé na sua nação (patriotismo). Ele também foi líder de um grupo de super-heróis cognominados Combatentes da Liberdade [Freedom Fighters] que lutaram e detiveram os nazistas num mundo alternativo, uma distópica Terra-X, onde a Segunda Guerra Mundial durou mais tempo do que em nossa realidade e que havia sido vencida pelos países da aliança do Eixo (Alemanha, Itália e Japão). Atualmente, esse personagem e sua Terra-X foram incorporados ao multiverso da editora DC comics.

A minissérie em quadrinhos U.S. Tio Sam, escrita por Steve Darnall e Alex Ross, que também faz a arte, foi publicada no 
Brasil em outubro de 1998 (Abril Jovem). Na sua edição original de 1997, a obra foi publicada pelo selo Vertigo, linha da editora DC comics especializada em histórias voltadas para o público adulto. A história, subdividida em duas edições, apresenta uma ficção política distópica no qual um dos mais conhecidos ícones culturais do mundo, o Tio Sam, realiza uma involuntária e extemporânea jornada ao âmago da nação que representa: os Estados Unidos da América do Norte. A viagem de um andrajoso Uncle Sam através da história e pelas ruas dos Estados Unidos é assolada pela constatação desoladora de que o sonho americano tornou-se tétrico e a terra da liberdade, inóspita.

\section{A análise da HQ a partir da filosofia política americana}

Diferentemente dos ícones predecessores homônimos citados anteriormente, o Tio Sam de Darnall e Ross (1998) não ostenta uma imagem austera e tampouco um ideário definido. Ele sequer tem consciência de sua identidade: não sabe se é um mendigo ébrio e alucinado vagando pelas ruas ou o espírito decadente da nação "desgastado pela autodestruição da América” e pelas doenças sociais - como adverte Ross.

A busca pela sua própria identidade faz com que Sam seja atormentado tanto por devaneios de um passado verídico e cruel da história dos EUA, quanto por traumas hodiernos que proliferam pelas ruas do país, e diante do qual não há como escapar de maneira incólume.

Nessa perspectiva, são exemplificados: o genocídio dos nativos americanos, a escravidão, o racismo, a intolerância sexual e religiosa, a corrupção, o desemprego, a violência, os assassinatos de Abraham Lincoln, John Kennedy e Martin Luther King, os generais latifundiários e os fazendeiros destituídos de suas propriedades, o poder midiático capitalista, os imigrantes explorados, a obsolescência de produtos e valores, os horrores da Guerra de Secessão, a Klu-Klux-Klan, as leis que beneficiam grandes corporações em detrimento dos pobres, as campanhas difamatórias e a perseguição política no macarthismo, o intervencionismo militar para garantir "interesses americanos” no México, Nicarágua, China, República Dominicana e Golfo Pérsico, Sacco e Vanzetti, Joe Hill e os Nove de Scotsboro, o crime organizado, Daniel Shays e a milícia de Massachussetts em 1786, os policiais de Chicago em 1893, a Guarda Nacional em 1970, dentre outros episódios. 
Diante de tal cenário desalentador Sam é ao mesmo tempo o protagonista da violência em profusão e o espectador involuntário de uma miríade de injustiças. E a possível redenção reside justamente na sua capacidade de reconhecer e assumir a responsabilidade por tais atos.

Embora o propósito deste artigo seja relacionar, ainda que de modo breve e lacunar, tópicos do comic book U.S. Tio Sam com algumas ideias dos dois principais filósofos políticos americanos da contemporaneidade, John Rawls (1921-2002) e Robert Nozick (1938-2002), nesta ocasião, restringiremos nossa exposição ao tema da liberdade. Entretanto, antes de indicarmos certos aspectos teóricos extraídos de Uma Teoria da Justiça (2000) e Anarquia, Estado e Utopia (1991) obras produzidas na Colúmbia (América), faremos uma rápida digressão para situar o tema da liberdade na Britannia (Inglaterra), com Sir Isaiah Berlin (1909-1997).

No ensaio Dois conceitos de Liberdade, Berlin (1980) afirma que é necessário distinguir entre dois tipos de liberdade: a negativa, compreendida como ausência de coerção; e a positiva, compreendida como possibilidade de autorrealização, isto é, plena e autodirigida, sem os impedimentos das forças culturais e sociais. Uma vez que os propósitos e os direitos do indivíduo (cidadão) nem sempre se coadunam com os objetivos definidos de uma sociedade estruturada (Estado), as duas noções de liberdade inevitavelmente se opõem.

Para Rawls (2000), um Estado democrático liberal deve garantir justiça social. O ideal de justiça (um dentre os vários possíveis) esboçado por ele propõe assegurar que os membros de tal sociedade sejam providos com direitos básicos e oportunidades mais ou menos iguais. A configuração desta sociedade teria como ponto de partida dois princípios fundamentais de justiça: primeiro, o estabelecimento de direitos básicos; e segundo, a igualdade de oportunidades (também chamado de "princípio da diferença"). Assim, na sua teoria da justiça como equidade temos respectivamente um princípio de liberdade e um princípio de igualdade.

Para combater as antinomias da sociedade democrática, particularmente aquelas que envolvem justiça/injustiça e opulência/miséria, Rawls (200o) propõe que os socialmente mais favorecidos atuem de maneira altruísta, no sentido de reparar as desigualdades que afligem os socialmente desfavorecidos. Na prática, isto implica no fato que uma parcela significativa da população teria de abdicar de forma consciente e benevolente de alguns privilégios e vantagens materiais, obtidas de forma legítima (por mérito, herança, virtude) em 
prol dos desvalidos.

Nozick (1991), por sua vez, ao analisar o Estado moderno critica as teses políticas do Conservadorismo, do Liberalismo e do Socialismo que, em instâncias distintas e por intermédio de ingerências diferentes acabam por violar os direitos individuais das pessoas. E, em conformidade com os termos definidos por sua filosofia libertária, infringir os direitos do indivíduo equivale a atentar contra a sua liberdade. Então, em contrapartida, ele defende a noção de um Estado Mínimo (um modelo político e econômico utópico), compatível com uma ética libertária baseada nos direitos e que seria legítimo e moralmente justificado, visto que, nestes termos, qualquer outra concepção mais abrangente de Estado inelutavelmente violaria os direitos (pessoais e de posse) do indivíduo. Trata-se de uma limitação considerável nas funções do Estado que ficam praticamente restringidas ao papel de defender seus cidadãos contra possíveis ataques (violência, roubo, fraude etc.) de outros indivíduos ou grupos.

Desse modo, Nozick (1991), contrário ao conceito de justiça distributiva, assevera que na teoria rawlsiana existe uma incompatibilidade entre os dois princípios fundamentais que constituiriam uma sociedade realmente justa: o princípio da diferença colidiria com o primeiro princípio, na medida em que ao abdicar de seus talentos naturais ou posse legítima ("justamente adquirida" ou "justamente transferida"), o indivíduo estaria sofrendo um tipo de intervenção na sua liberdade. Deste modo, Nozick acusa Rawls de não defender a liberdade como o valor maior em qualquer sociedade, mas de eleger a igualdade como o valor supremo.

Na interpretação original de Darnall e Ross (1998), há pelo menos duas descrições alternativas e opositoras para o emblemático Tio Sam.

Na primeira versão, ele é o ícone do maior Império capitalista mundial, os Estados Unidos, que sempre apela para a Verdade (Truth), que é a sua Verdade absoluta para, conforme os seus interesses políticos, econômicos e ideológicos, "justificar" todos os eventos trágicos anteriormente mencionados.

Na segunda versão, ele é um símbolo desacreditado da democracia liberal, da América, cuja ideia de responsabilidade social reside, sobretudo, no primado da Liberdade (Freedom) para todos.

Assim, ocorre um inevitável gládio alegórico: a força versus o diálogo. E a aposta dos autores deste romance gráfico reside no Tio Sam que personifica a Liberdade (aliás, que caracteriza uma dentre as possíveis faces da liberdade). E em 
conformidade com a descrição oferecida nessa saga imagética e textual, somos admoestados a permanecer atentos com relação ao outro Tio Sam que personifica a Verdade e que é justamente o amálgama de tudo aquilo que obsta as liberdades individuais, visto que se trata de uma espécie velada de um Estado totalitário.

\section{Considerações finais}

Diante do exposto, embora haja nítidas divergências entre as teorias sociais dos filósofos políticos John Rawls (2000) e Robert Nozick (1991), podemos entrever nos escritos de ambos um forte antagonismo ao tipo de regime político, econômico e de organização social "representado" pelo Tio Sam da Verdade totalitária.

Desse modo, tal como o Tio Sam idealizado para reivindicar sua "consciência social sobre a América", na perspectiva de Darnall e Ross (1998), a noção de Liberdade defendida por Rawls (2000) e Nozick (1991) nem sempre possui traços definidos e conciliadores: seus matizes, assim como seus contrastes, ora advém do Liberalismo, ora do Libertarismo.

Finalmente, assim como ocorre na obra de Darnall e Ross (1998), esperamos que após o inevitável confronto entre as duas versões de Tio Sam, emerja vitorioso aquele que carrega as multidiversificadas cores da bandeira da liberdade. Embora saibamos que, na contemporaneidade, sombrias versões alternativas sempre rondam as sociedades democráticas e liberais em terras paralelas não tão distantes (Talvez seja melhor seguirmos o exemplo de liberdade de Corto Maltese, de Hugo Pratt, e não acreditar nem em dogmas e tampouco em bandeiras...).

\section{Referências}

ALEX ROSS INTERVIEW (2001). Disponível em: <http:// www.comicbookresources.com/?page $=$ article\&id $=243>$. Acesso em: 03 jul. 2016.

BAGGINI, Julian. Para que serve tudo isso?: a filosofia e o sentido da vida, de Platão a Monty Python. Rio de Janeiro: Jorge Zahar, 2008.

BERLIN, Isaiah. Dois conceitos de liberdade. In: KING, Preston. O estudo da política. Brasília: Editora UNB, 198o. p. 107-142.

CAGNIN, Antônio Luiz. Os quadrinhos. São Paulo: Ática, 
1975.

CALAZANS, Flávio Mário de Alcântara. Uma abordagem midiológica das histórias em quadrinhos no ciberespaço. $R e$ vista ARTEunesp, São Paulo, n. 12, p. 147-156, 1996.

Bibliografia sobre Histórias em quadrinhos com resenhas críticas. In: CALAZANS, Flávio Mário de Alcântara (Org.). As histórias em quadrinhos no Brasil: teoria e prática. São Paulo: INTERCOM, 1997.

CATHCART, Thomas; KLEIN, Daniel. Platão e um ornitorrinco entram num bar...: a filosofia explicada com senso de humor. Rio de Janeiro: Objetiva, 2008.

CIRNE, Moacy. A crítica e os críticos de quadrinhos. Revista de Cultura Vozes, Petrópolis-RJ, v. 68, n. 4, p. 311-315, out. 1974 .

Quadrinhos: sedução e paixão. Petrópolis-RJ: Vozes, 2000.

COHEN, Martin. Casos filosóficos. Rio de Janeiro: Civilização Brasileira: 2012.

DARNALL, Steve; ROSS, Alex. U.S. Tio Sam. São Paulo: Abril Jovem, 1998.

DELEUZE, Giles. Uma conversa, o que é, para que serve? In: DELEUZE, Giles; PARNET, Claire. Diálogos. São Paulo: Escuta, 1998.

DORFMAN, Ariel; JOFRÉ, Manuel. Super-Homem e seus amigos do peito. Tradução de Roberto Moses Pechman e Felipe Doctors. Rio de Janeiro: Paz e Terra, 1978.

DORFMAN, Ariel; MATTELART, Armand. Para ler o Pato Donald: comunicação de massa e colonialismo. $2^{\text {a }}$ ed. Tradução de Álvaro de Moya. Rio de Janeiro: Paz e Terra, 1980.

ECO, Umberto. Apocalípticos e Integrados. São Paulo: Perspectiva, 1993.

EISNER, Will. Quadrinhos e Arte Sequencial. $3^{\mathrm{a}}$ ed. São Paulo: Martins Fontes, 1999.

FERNANDES, Anchieta. Presença do quadrinho socialista. Revista de Cultura Vozes, Petrópolis-RJ, v. 71, n. 8, p. 645651, out. 1977.

GOODENOUGH, Jerry. A philosopher goes to the cinema. In: READ, Rupert; GOODENOUGH, Jerry. Film as Philosophy: Essays on the cinema after Wittgenstein and Cavell. New York: Palgrave MacMillan, 2005. p. 1-29.

LUYTEN, Sonia Maria Bibe (Org.). Histórias em quadrinhos - leitura crítica. 2⿳亠丷厂 ed. São Paulo: Edições Paulinas, 1985.

liense, 1987 . 
Mangá - O poder dos quadrinhos japoneses. São Paulo: Estação Liberdade, 1991.

LYING IN THE GUTTERS (2003). Disponível em: <http:// www.comicbookresources.com/?page $=$ article $\& i d=14571>$. Acesso em: 03 jul. 2016.

MAGALHÃES, Henrique. Fanzine: comunicação popular e resistência cultural. Visualidades, v. 7, n. 1, abr. 2012. Disponível em: <http://www.revistas.ufg.br/index.php/VISUAL/ article/view/18121/10810 >. Acesso em: 27 nov. 2015.

MARINOFF, Lou. Mais Platão, menos prozac: a filosofia aplicada ao cotidiano. Rio de Janeiro: Record, 2006.

MARNY, Jacques. Sociologia das histórias aos quadradinhos. Porto: Companhia Editora do Minho, 1970.

McLAUGHLIN, Jeff. Comics as Philosophy. Jackson: University of Mississipi Press, 2005.

MIX, Miguel Rojas. Los heroes estan fatigados: el comic cien años después. Casa de las Américas, Havana/Cuba, v. 27, n. 207, p. 1-5, abr-jun. 1997.

MORRIS, Matt; MORRIS, Tom. Super-heróis e a filosofia. São Paulo: Madras, 2009.

MOYA, Álvaro. Shazam!. $3^{a}$ ed. São Paulo: Perspectiva, 1977. História das Histórias em Quadrinhos. São Paulo: Brasiliense, 1994.

. Vapt-Vupt. São Paulo: Clemente \& Gramani Editora, 2003.

NEOTTI, Clarêncio (Org.). O mundo dos super-heróis. Revista de Cultura Vozes, Petrópolis-RJ, v. 65, n. 4, p. 255-366, maio 1971.

. Quadrinhos e ideologia. Revista de Cultura Vozes, Petrópolis-RJ, v. 67, n. 7, p. 519-591, set. 1973.

NOZICK, Robert. Anarquia, Estado e Utopia. Rio de Janeiro: Zahar, 1991.

OLIVEIRA, Guilherme Magalhães Vale de Souza. Da popularização da filosofia à expertise filosófica: uma problematização do papel do intelectual na mídia (Revista CULT 19972013). 2015. 189 f. Dissertação (Mestrado em Educação) Universidade de São Paulo, São Paulo-SP, 2015.

POWERS, William. O BlackBerry de Hamlet: uma filosofia prática para viver bem na era digital. São Paulo: Editora Alaúde, 2012.

RAMA, Angela; VERGUEIRO, Valdomiro. Como usar as histórias em quadrinhos na sala de aula. São Paulo: Contexto, 2007. 
RAMOS, Paulo. A leitura dos quadrinhos. São Paulo: Contexto, 2010.

RAWLS, John. Uma teoria da justiça. São Paulo: Martins Fontes, 2000.

ROOS, Theo. Vitaminas filosóficas: a arte de bem viver. Rio de Janeiro: Casa da Palavra, 2006.

. Novas vitaminas filosóficas: receitas para uma boa vida. Rio de Janeiro: Casa da Palavra, 2008.

VERGUEIRO, Valdomiro; RAMOS, Paulo. Quadrinhos na educação. São Paulo: Contexto, 2009.

Recebido em: 29/11/15

Aceito em: 11/06/16

\footnotetext{
HERALDO APARECIDO SILVA

heraldokf@yahoo.com.br

Doutor em Filosofia pela Universidade Federal de São Carlos (UFSCAR). Mestre em Educação pela Universidade Estadual Paulista (UNESP). Graduado em Filosofia pela Universidade Estadual Paulista (UNESP). Professor de Filosofia da Educação da Universidade Federal do Piauí (UFPI) e Coordenador do Núcleo de Estudos em Filosofia da Educação e Pragmatismo da UFPI.
} 